\title{
Redução da maioridade penal: a longa trajetória de um discurso sobre adolescentes
}

\section{Pedro Rolo Benetti* (1)}

\section{Resumo}

Entre os anos 1980 e 1990 foi possível observar, no Brasil, um momento de expansão da rede de proteção à infância e adolescência, a partir da adoção de marcos legais paradigmáticos, como o Estatuto da Criança e do Adolescente (1990). No entanto, ainda antes da promulgação do ECA, em 1989, foi apresentada proposta de emenda constitucional para a alteração do artigo 228, que versa sobre a idade mínima para a imputabilidade penal. Desde então, diversos atores sociais e políticos se empenharem em preservar no debate público o espaço para uma visão do jovem como problema, a demandar solução pela via punitiva. A proposta deste artigo é analisar as falas dos parlamentares envolvidos nas discussões da PEC 171-93, conhecida como redução da maioridade penal, aprovada em 2015 na Câmara dos Deputados. A partir das atas de plenário e comissões especiais da CD, pretendese compreender como se conformou nesse espaço uma perspectiva da juventude como possível fonte de violência. Dentre os muitos argumentos empregados pelos defensores da medida, destacam-se três, a serem discutidos em maior profundidade: (1) transformações na capacidade de entendimento dos jovens em relação a 1940, quando foi redigido o código penal; (2) exemplaridade da punição e seus efeitos sobre a organização das famílias; e (3) possibilidade de oferecer uma resposta às vítimas de violência cometida por menores de idade.

Palavras-chave: maioridade penal, discurso, violência, punição, legislativo.

* Universidade de São Paulo, São Paulo, SP, Brasil. 


\section{Lowering the age of criminal responsibility: the long run of a discourse on adolescents}

\section{Abstract}

Between the 1980s and 1990s, Brazil experienced an era of expansion of childhood and adolescence protection networks, based on the adoption of paradigmatic legal frameworks, such as the Child and Adolescent Statute (1990). However, even before the enactment of the ECA, in 1989, a proposal for a constitutional amendment was presented to amend article 228, which deals with the minimum age for criminal liability. Since then, several social and political actors have endeavored to preserve in the public debate the space for a vision of the youth as a problem, demanding a solution through punitive measures. The purpose of this article is to analyze the speeches of the parliamentarians involved in the discussions of the PEC 171-93, known as the reduction of the penal age, approved in 2015 in the Chamber of Deputies. From the minutes of the plenary and special commissions of the CD, it is intended to understand how a perspective of youth as a source of violence was formed in this space. Among the many arguments used by defenders of the measure, three stand out, to be discussed in greater depth: (1) changes in the understanding of young people in relation to 1940, when the penal code was drafted; (2) exemplarity of punishment and its effects on the organization of families; and (3) the possibility of offering a response to victims of violence committed by minors.

Keywords: criminal majority, speech, violence, punishment, legislative.

\section{Introdução}

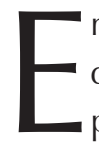

m agosto de 2019, durante seu primeiro ano de mandato, o presidente da República, Jair Bolsonaro pediu ao presidente do Senado que pautasse a apreciação da proposta destinada a reduzir a maioridade penal no país. ${ }^{1}$ Pouco tempo depois, seu filho mais velho, senador pelo Rio de Janeiro, protocola proposta de emenda constitucional sugerindo a mudança do artigo 228 da Constituição Federal, buscando novo impulso

\footnotetext{
1 Ver https://agenciabrasil.ebc.com.br/politica/noticia/2019-08/bolsonaro-defende-votacaoda-pec-da-maioridade-penal-no-senado
} 
à pauta. ${ }^{2}$ Levando em consideração que já existe texto aprovado em dois turnos na Câmara dos Deputados sobre o mesmo tema, pode-se questionar a pertinência das novas propostas apresentadas. Por alguma razão, a redução da maioridade penal permanece no horizonte de políticos conservadores, como forma de mobilização de suas bases, como estratégia de influência sobre o debate público, como mecanismo de reativação de discursos já sedimentados no imaginário social acerca do encontro nem sempre harmonioso entre punição, ordem, direitos humanos, cidadania e democracia. Em 2019, mesmo passados quatro anos da tramitação de uma matéria dessa natureza na Câmara, segue fazendo sentido para um senador apresentar proposta de redução da maioridade penal.

A longa e inconclusa trajetória dos debates sobre a redução da maioridade penal acompanha, em boa medida, as próprias disputas sobre a construção de noções fundamentais para a vida política de qualquer sociedade, como as mencionadas acima: direito, cidadania, ordem, punição. No caso brasileiro, o processo de redemocratização do país constitui marco fundamental para a reorganização da sociedade e do Estado. Nesse sentido, podemos afirmar que, pelo menos desde a promulgação da constituição federal de 1988, é possível observar uma série de disputas em torno da conformação mais ou menos punitiva do Estado, mais ou menos abrangente das noções de cidadania e do rol de direitos assegurados aos cidadãos. Desde aquele momento, houve forças sociais que avançaram pautas associadas a uma linguagem de direitos, como as que construíram o Estatuto da Criança e do Adolescente (ECA) (Brasil, 1990) e outras que se empenharam em circular uma perspectiva da juventude como ameaça, risco e desordem. Essas últimas se articularam no parlamento brasileiro e, em diversos momentos, tentaram avançar uma agenda restritiva em relação aos direitos de crianças e adolescentes. Seu mote de organização tem sido, desde o fim dos anos 1980, a reivindicação pela redução da maioridade penal. Para compreender como tais atores - antes amplamente minoritários

${ }^{2}$ Ver https://istoe.com.br/proposta-de-flavio-bolsonaro-para-reduzir-maioridade-penal-aguardavotacao-na-ccj/ 
e hoje mais fortalecidos - articularam suas posições ao longo dos anos, nos propusemos a analisar toda a documentação relativa à tramitação da Proposta de Emenda à Constituição (PEC) 171-93, aprovada em 2015 na Câmara dos Deputados depois de 22 anos de tramitação no congresso. Para cumprir esse objetivo, o texto que segue se divide em quatro tópicos, sendo o primeiro uma discussão sobre como os discursos sobre juventude e violência nos ajudam a compreender disputas sociais e políticas em curso; o segundo, uma breve apresentação do percurso da matéria no ambiente da Câmara dos Deputados; o terceiro, uma sistematização dos argumentos em defesa da redução da maioridade penal; e o quarto, uma discussão sobre a imagem do adolescente que pode ser extraída dos discursos parlamentares aqui analisados.

\section{A fala da juventude e a atualização de discursos sobre violência}

Os debates sobre a redução da maioridade penal podem ser lidos em relação a diferentes temporalidades da formação social e política brasileira. Isso quer dizer que as falas dos parlamentares que defendem essa medida mobilizam temas, argumentos e discursos cujos elementos mais importantes apareceram em momentos históricos variados, em diálogo com questões e conjunturas específicas. Em analogia com as noções de duração mobilizadas por Braudel (1965), poderíamos perceber nos discursos sobre violência e punição camadas que remetem a durações distintas. Estão presentes o tempo longo da formação ibérica, com as reivindicações por punições espetaculares, exacerbadas e exemplares (Batista, 2015); o tempo mais próximo das reflexões criminológicas do começo do século 20, com suas afirmações sobre os riscos da juventude e suas perspectivas menoristas (Alvarez, 1989); e também o tempo mais recente das últimas décadas de regime democrático, no qual diversos empreendedores morais têm construído suas participações no debate público a partir da reivindicação 
por punições maiores e mais duras para os criminosos (Garland, 2008; Simon, 2017; Caldeira, 1991; Higa; Alvarez, 2019).

Esses elementos podem ser observados nos discursos enunciados em diferentes espaços sociais, da imprensa à academia, das instituições dos sistemas repressivos do Estado (polícia/justiça criminal) aos espaços de representação política. Em todos esses lugares é possível encontrar falas em defesa da redução da maioridade penal. Tais falas sustentam uma visão mais geral de sociedade, constroem uma imagem do adolescente (em particular daqueles considerados infratores) e se relacionam com discursos mais amplos sobre punição, violência, direitos humanos, criminalidade e, em última instância, cidadania. Ao olhar para a passagem dos anos 1980 para os 1990, Teresa Caldeira (2000) apresentou a noção de fala do crime para compreender a maneira pela qual vários sujeitos sociais organizavam seus parâmetros de justiça, suas noções de bem e suas demandas por punição. O que pretendemos, aqui, é observar, em alguma medida, uma fração dessa fala do crime, recortando a maneira como parlamentares eleitos falam sobre os adolescentes em conflito com a lei, uma espécie de fala da juventude.

Ao analisar seus discursos, temos a possibilidade de investigar os caminhos para a atualização de perspectivas sobre punição e ordem social. Partimos do suposto de que a ativação dos elementos punitivos de nossa formação histórica no presente depende do trabalho empenhado de atores sociais dispostos a atualizar simbolicamente o lugar da violência no funcionamento de nossa vida social. Isto é, o uso corrente de expedientes violentos como mecanismo de resolução dos conflitos sociais, que se encontra na raiz de demandas por punições mais duras (e mais longas, para mais segmentos da sociedade), não pode ser depreendido apenas do exame das grandes estruturas seculares que conformam nosso mundo. Para que essas estruturas de fato funcionem em cada momento histórico, elas dependem de atores dispostos a torná-las operacionais. Em outras palavras, não basta focalizar a escravidão ou os regimes políticos autoritários para compreender por que circulam, até hoje, discursos que defendem 
soluções violentas para os conflitos sociais. É preciso olhar também para a maneira como certos atores, em cada momento, atualizaram discursos que legitimam a continuidade e adaptação de determinadas práticas sociais às suas condições presentes. Para exemplificar, a compreensão do uso da tortura em nossa sociedade não passa apenas pelo fato de que há uma longa tradição de castigos corporais em nossa formação social. Ela exige que façamos o exercício de investigar (i) quais foram os atores que, nos diferentes momentos de nossa história, se valeram de práticas existentes anteriormente, adaptando-as a novas condições sociais e políticas e (ii) quais foram os discursos que deram suporte a essas práticas, encontrando lugar para sua legitimação na ordem social vigente. As razões para a persistência de perspectivas punitivistas nas falas sobre infância, adolescência e juventude nos exige, portanto, o mesmo movimento de compreensão dos caminhos para a atualização de práticas sociais e discursos, considerando suas diferentes camadas temporais e o trabalho ativo de determinados atores sociais para que continuem existindo (Foucault, 1999, 2005).

O foco deste trabalho recai, assim, nos discursos de um segmento específico, os representantes eleitos. Por meio da análise de suas falas, pretendemos verificar as continuidades e rupturas em relação a discursos anteriormente existentes. Mesmo antes da aprovação da redução da maioridade penal na Câmara dos Deputados, acadêmicos já se debruçavam sobre os debates em torno da medida, constantemente evocada por políticos e meios de comunicação como solução para o aumento da criminalidade violenta (Campos, 2009; Budó, 2013b). Há trabalhos dedicados a compreender de que maneira o tema foi retratado na imprensa, outros que lançam seu olhar também sobre o sistema político (Budó; Cappi, 2018; Kwen, 2016; Corte Real; Conceição, 2013) e ainda os que cruzam informações, apontando para a maneira como imprensa e atividade política institucional se alimentam mutuamente. Os textos sobre a forma como as mídias mobilizam os projetos legislativos de redução da maioridade penal mostram que, em grande medida, o debate tende 
a ganhar fôlego quando casos envolvendo adolescentes apresentam grande repercussão e geram algum tipo de comoção na opinião pública (Campos, 2009; Budó, 2013b; Budó, 2015a; Budó; Cappi, 2018; Cunha, 2015; Campos et al., 2015).

No que diz respeito aos textos que centram seu foco nos espaços da política institucional, há diferenças no número de propostas legislativas que embasam cada pesquisa, bem como no foco das análises dos discursos, que se concentram em aspectos diferentes da vida parlamentar. Enquanto algumas se concentram nas manifestações no curso do processo de tramitação, olhando para audiências, sessões em comissões e discursos em plenário, outros textos centram sua atenção no próprio conteúdo dos projetos de lei e nas justificativas que os acompanham.

Budó e Cappi (2018) analisam apenas as sessões nos plenários da Câmara dos Deputados e do Senado que discutiram os projetos de redução da maioridade penal e aumento do tempo de internação. Já Kwen (2016) reuniu diversos Projetos de Lei (PL) e Propostas de Emenda Constitucional (PEC) para observar tanto a direção das alterações propostas quanto as falas de parlamentares nos diferentes espaços institucionais. Corte Real e Conceição (2013) se dedicam a 13 documentos com propostas de alteração legislativa e os votos de relator acerca das mesmas, também com o objetivo de compreender como os parlamentares constroem suas representações. $\mathrm{O}$ caminho escolhido para o presente trabalho resultou no acompanhamento do processo de tramitação da PEC 171/93 na Câmara, sistematizando os argumentos apresentados nos debates em comissões e plenário, o que exigiu leitura atenta de todos os registros produzidos nas mais de duas décadas de tramitação da matéria. Foram esses os registros investigados como parte do esforço de compreender os caminhos de atualização de discursos sobre punição no parlamento brasileiro.

Para tanto, o procedimento de pesquisa aqui adotado consistiu na leitura sistemática das atas de todas as reuniões em que foi discutida essa matéria no âmbito legislativo. Em outras palavras, todas as sessões de 
comissões, subcomissões e plenário das duas casas congressuais em que se deliberou sobre o tema da redução da maioridade penal tiveram suas atas lidas e organizadas de maneira a separar os posicionamentos contrários e favoráveis à matéria e assim organizar os argumentos empregados por seus defensores. O corpus de pesquisa consistiu, portanto, na totalidade das falas enunciadas na Câmara dos Deputados em favor da alteração do artigo 228 da Constituição com o objetivo de diminuir a idade limite para que um cidadão seja considerado penalmente inimputável. Ficaram excluídas da leitura e sistematização apenas as propostas (e suas justificativas) que não chegaram à discussão em nenhuma sessão de qualquer das instâncias do poder legislativo. Não é possível quantificar esses discursos, na medida em que foram falas extraídas de sessões de deliberação, onde os mesmos parlamentares se pronunciam diversas vezes, à diferença das manifestações de plenário. ${ }^{3}$

\section{A redução da maioridade penal na Câmara dos Deputados}

Compreender o funcionamento do discurso, no caso específico de nossa análise, significa também um movimento na direção de entender as regras que o conformam em diferentes espaços. Nesse sentido, a presente pesquisa exigiu mapear uma linguagem particular à vida das instituições políticas formais, dos percursos atravessados por uma matéria em deliberação aos modos de falar/interditar as discussões sobre determinados temas por meio de expedientes como a reivindicação de inconstitucionalidade. Antes de falar propriamente dos argumentos mobilizados pelos defensores da redução, faz-se necessária uma breve apresentação desse ambiente no qual as discussões se deram.

\footnotetext{
${ }^{3}$ Por meio da página de informações da Câmara dos Deputados é possível rastrear todo o percurso de uma proposta legislativa, identificando com precisão as datas de reuniões em que o tema foi pautado. Assim, torna-se possível baixar as atas ou áudios e proceder à análise, No caso da PEC 171/93 o percurso de tramitação encontra-se disponível em: www.camara.leg.br/proposicoesWeb/fichadetramitacao?idProposicao=14493. A lista de atas citadas no curso deste artigo é apresentada como anexo ao final do texto.
} 


\section{O processo de tramitação}

O levantamento de documentos relativos ao processo de tramitação de medidas que visassem à redução da maioridade penal na Câmara dos Deputados revela que apenas cinco anos após a promulgação da Constituição Federal de 1988 (CF), o deputado Benedito Domingos (Distrito Federal), eleito pelo Partido Progressista (PP), apresentou a Proposta de Emenda à Constituição de número 171 (PEC 171-1993), cujo objetivo era alterar a redação do artigo 228 da carta magna, reduzindo de 18 para 16 anos a idade mínima para a imputabilidade penal. Entre o dia 18 de agosto de 1993, data em que a matéria foi apresentada, e o dia 19 de agosto de 2015, quando foi aprovada em segundo turno no plenário da Câmara, transcorreram 22 anos nos quais o tema desapareceu e reapareceu na agenda dos deputados federais de sete legislaturas diferentes. Antes da PEC 171-93, o deputado gaúcho Telmo Kirst (PDS), apresentara a Proposta de Emenda à Constituição número 14, em 18 de maio de 1989. No entanto, tal proposta foi prejudicada pela mesa diretora da Câmara dos Deputados em 1994, em decorrência do encerramento dos trabalhos de revisão constitucional. Ao longo dos 22 anos de tramitação da PEC 171-93 foram apresentadas outras 39 propostas de alteração do artigo 228 da CF, sendo 38 delas apensadas à PEC original e uma devolvida ao autor por não preencher os requisitos formais (PEC 302, de 2013). Desde a primeira proposta, somente nos anos de 1994, 1998, 2006, 2008 e 2010 não foram apresentadas quaisquer propostas de alteração do artigo 228.

Em paralelo às iniciativas que objetivavam reduzir a maioridade penal e abordar os problemas de adolescentes em conflito com a lei pela via punitiva, os movimentos sociais ligados à proteção da infância e da adolescência se articulavam para construir uma legislação que assegurasse um amplo rol de direitos para este segmento da sociedade. Já na constituinte esses movimentos pressionaram pela adoção de uma série de prerrogativas, que seriam confirmadas pela lei que regulamentaria os dispositivos constitucionais sobre o tema, o ECA. O Estatuto da Criança e do Adolescente foi instituído 
pela Lei 8069 de 13 de julho de 1990, regulamentando o art. II Prefácio 227, da Constituição Federal de 1988, e se constitui no marco legal e regulatório dos direitos humanos de crianças e adolescentes no Brasil. Seu perfil reflete duplamente o contexto interno de abertura política e redemocratização que o país vivia à época, somado à incorporação de uma série de normativas internacionais emergentes sobre o tema, como a Declaração dos Direitos da Criança (1959), as Regras mínimas das Nações Unidas para administração da Justiça da Infância e da Juventude (conhecidas como Regras de Beijing, 1985) e as Diretrizes das Nações Unidas para prevenção da Delinquência Juvenil (1988).

Os princípios gerais que balizaram o ECA absorveram os ditames da doutrina da proteção integral e o princípio da prioridade absoluta previstos na nova Constituição. Substituindo o antigo e controverso Código de Menores (Lei 6697/79), a partir dessa regulamentação, as crianças brasileiras - assim consideradas formalmente até os 12 anos incompletos - e os adolescentes - dos 12 aos 18 anos - passaram a ser considerados sujeitos de direitos fundamentais e individuais, em sua peculiar condição de "pessoas em desenvolvimento", sem distinção de raça, classe social ou qualquer forma de discriminação.

A partir de 2012, a rede de atores estatais e da sociedade civil envolvidos com a aplicação e acompanhamento de medidas socioeducativas passou a ser organizada no Sistema Nacional de Atendimento Socioeducativo (Sinase), instituído pela lei 12.594/2012. Chama atenção o fato de que dentre tantos atores envolvidos diretamente com as medidas punitivas aplicadas a menores de idade, desde juízes ou administradores de instituições estaduais a organizações da sociedade civil, nenhum tenha sido chamado a falar na comissão especial que avaliou o mérito da medida, formada em 2015. O processo de tramitação da redução da maioridade penal, se analisado em paralelo ao desenvolvimento de um sistema de proteção às crianças e aos adolescentes, pode ser considerado emblemático da reorganização do debate público brasileiro, que progressivamente fecha espaço para a articulação de novos direitos e abre as portas para soluções que se baseiem 
exclusivamente numa visão de mundo punitivista, que entende o direito penal como solução única para os conflitos sociais. Se é verdade que, desde o processo de transição, sempre existiram tanto grupos que pressionavam pela expansão dos direitos quanto outros que se articulavam em torno de plataformas punitivas - como demonstra a longa trajetória de projetos apresentados com o fito de reduzir a maioridade penal -, é preciso observar também que as disputas políticas mais emblemáticas dos anos 1990 e 2000 não se deram em torno de pautas como a analisada aqui.

Por mais que tenha sido um tema permanente desde a promulgação da $C F$, não se pode dizer que a redução da maioridade penal tenha desempenhado papel central na organização das disputas políticoinstitucionais até a legislatura que iniciou seus trabalhos em fevereiro de 2015. Em dezembro de 1993, a mesa diretora da Câmara transformou a PEC 171-93 em emenda revisional, assim como a PEC 14-1989, o que a levou a ser prejudicada em função do encerramento dos trabalhos de revisão da CF de 1988. O deputado Benedito Domingos requereu, então, o retorno da PEC 171-93 à Câmara, já em março de 1995, em nova legislatura. Após relatoria de José Luiz Clerot (PMDB-PB) na Comissão de Constituição e Justiça da Câmara (CCJC), os deputados Alexandre Cardoso (PSB-RJ), Marcelo Deda (PT-SE), Helio Bicudo (PT-SP), Zulaiê Cobra (PSDB$\mathrm{SP})$ e Milton Mendes (PT-SC) pedem vista do processo e o mesmo não chega à fase de votação. No curso dos anos de 1996, 1997 e 1998 não há atividade em relação à matéria, que retoma sua tramitação em fevereiro de 1999 com a designação de novo relator na CCJC, Inaldo Leitão (PL-PB).

Nos últimos meses daquele ano, foram realizadas duas audiências na Câmara dos Deputados com o objetivo de ouvir cidadãos considerados especialistas no tema ou representantes de posições legítimas num debate dessa natureza. Já aqui aparece um dado que se tornaria estruturante das argumentações futuras daqueles que são contra ou a favor da redução da maioridade penal: enquanto os deputados favoráveis à redução tendem a buscar os relatos de experiências individuais ou familiares 
de sofrimento causado pela violência praticada por menores, aqueles que são contra a redução recorrem à fala de representantes dos setores organizados da sociedade ligados ao mundo jurídico, como a OAB, ou diretamente envolvidos com os temas da infância e adolescência, como a UNICEF e a ABRINQ.

Depois de diversas idas e vindas ao longo dos anos, com diferentes relatores e pareceres acerca da admissibilidade do texto, em 2015, entre março e junho, ocorre todo o rito legislativo que resulta na aprovação da emenda aglutinativa ${ }^{4}$ em primeiro turno, um dia após votação que rejeitou a redução da maioridade penal por uma diferença de cinco votos. Nos meses de março, abril, maio e junho, a PEC 171-93 teve sua admissibilidade discutida, votada e aprovada na CCJC, passou a uma Comissão Especial (CE) destinada a avaliar seu mérito, onde foi votada e aprovada, chegou ao plenário da Câmara, no qual o texto do substitutivo apresentado pela CE foi rejeitado, e, no dia seguinte desta rejeição, foi aprovada em primeiro turno na forma de uma emenda aglutinativa - cuja legalidade foi questionada por seus opositores no Supremo Tribunal Federal (STF) . Em agosto de 2015, o processo de tramitação da PEC na Câmara dos Deputados foi finalizado com a votação da matéria em segundo turno e o envio da mesma ao Senado Federal.

O desequilíbrio entre o longo processo de tramitação anterior à legislatura iniciada em 2015 - com seus muitos arquivamentos e desarquivamentos, diferentes relatores, requerimentos, PECs apensadas, audiências etc. - e o acelerado ritmo que a tramitação da matéria ganhou a partir de fevereiro daquele ano só pode ser explicado por um elemento da conjuntura: a eleição do deputado Eduardo Cunha (PMDB-RJ) para a presidência da Câmara, com uma plataforma de enfrentamento em relação ao poder executivo e independência do legislativo no estabelecimento de sua agenda

${ }^{4}$ Emendas destinadas a fundir textos de diversas emendas ou fundir texto de emenda com proposição original, conforme explicado pela própria página da Câmara dos Deputados: https://www.congressonacional.leg.br/pt_BR/legislacao-e-publicacoes/glossario-legislativo/-/ legislativo/termo/emenda_aglutinativa 
de trabalhos 5 . A tramitação da PEC 171-93 pode ser entendida, até certo ponto, como uma espécie de projeto piloto do processo de impeachment que se desenrolaria no ano seguinte. Naquele momento, o presidente da Câmara, opositor ferrenho do executivo, testa expedientes e consolida a formação de um bloco sólido o suficiente para aprovar matéria contrária ao interesse do governo em dois turnos, com maioria qualificada. É digno de nota, portanto, que a aprovação da redução da maioridade penal se confunde, em alguma medida, com a própria crise recente da democracia no Brasil.

\section{As discussões em torno da constitucionalidade}

As discussões em torno da redução da maioridade penal na Câmara dos Deputados podem ser divididas em duas etapas, sendo uma primeira centrada na constitucionalidade ou não da matéria e a segunda no mérito. Enquanto a primeira etapa seria responsabilidade da CCJC, a segunda transcorreria em uma comissão especial e, posteriormente, no plenário da casa. Na prática, os debates sobre a constitucionalidade e o mérito de se reduzir a maioridade penal se interpenetraram.

A PEC171-93 teve diversos relatores no curso de seu processo de tramitação na Comissão de Constituição, Justiça e Cidadania (CCJC). Foram eles os deputados José Luiz Clerot (PMDB-PB), Inaldo Leitão (então PSDB-PB), Marcelo Itagiba (então PMDB-RJ e depois PSDB-RJ), Osmar Serraglio (PMDB-PR) e Luiz Couto (PT-PB). Em todas as ocasiões nas quais se produziram pareceres em torno da constitucionalidade da PEC, a polêmica se resumiu à consideração do artigo 228 como garantia fundamental ou não.

\footnotetext{
${ }^{5}$ Cabe notar que a Ciência Política brasileira converge, de maneira geral, no diagnóstico acerca de um peso preponderante do poder executivo em suas relações com o legislativo. Para além dos instrumentos de incidência sobre a agenda legislativa, há estudos, como o de Figueiredo e Limongi (1999), que identificam que mais de $80 \%$ das matérias aprovadas no poder legislativo tem origem no Executivo. Nesse sentido, a posição de Cunha representa uma ruptura em relação aos padrões constituídos de funcionamento da democracia brasileira na Nova República.
} 
Em diversos momentos, a constituição de 1988 é atacada como um todo, considerada excessivamente garantista ou irrealizável. Segundo Chaloub (2016), uma das características do que se identifica como "nova direita" é justamente uma relação tensa com o texto de 1988 que, em muitos aspectos, seria considerado amplo e rígido demais. Após a rejeição do parecer do relator Luiz Couto (PT-PB), que recomendou a inadmissibilidade da matéria, foi votado novo parecer, do deputado Marcos Rogério (então PDT-RO, hoje no DEM), recomendando a admissibilidade. No texto, ele seguiu linha diferente do jurista que foi à comissão defender a admissibilidade da matéria. Ao invés de falar na modulação de uma cláusula pétrea, Rogério sustentou que o artigo 228 não configura uma das cláusulas pétreas da constituição.

Encerrados os trabalhos na CCJC, em meio a muitas discussões acaloradas e até mesmo brigas, 42 deputados votaram pelo parecer do novo relator Marcos Rogério e 17 votaram contra, não havendo nenhuma abstenção. As discussões sobre a constitucionalidade do tema seguiram durante todo o processo legislativo, trazidas principalmente pelos opositores da matéria. A etapa seguinte do processo legislativo foi a constituição de uma comissão especial para debater o mérito da redução. Foi nesse espaço, além do plenário, que encontramos um campo mais fértil para compreender quais são, como se relacionam e como são apresentados os argumentos daqueles que defendem essa medida restritiva como peça fundamental de sua visão de mundo.

\section{Os argumentos em defesa da redução da maioridade penal}

Tal como descrito anteriormente, o processo de tramitação da PEC 171-93 teve poucos desenvolvimentos nos 22 anos que separaram a sua proposição, em 1993, da sua aprovação, em 2015. Somente no ano de 2015 se intensificam os debates em torno da matéria, com reuniões constantes, tanto na CCJC quanto na Comissão Especial, exclusivamente dedicadas ao tema. Em meio às pressões da presidência da casa pela aceleração do rito legislativo, diversos foram os argumentos apresentados 
em defesa da redução. No curso dos poucos meses em que a matéria atravessou todo o processo legislativo na Câmara dos Deputados, muitos parlamentares se manifestaram sobre o tema. Mesmo os que não eram integrantes da CCJC ou da CE compareceram algumas vezes às sessões para registrar suas posições em matéria considerada central. É seguro afirmar que nenhum deputado - pelo menos nas comissões - se absteve de afirmar suas posições com relação à redução da maioridade penal. Todos pareciam ter a convicção de que reforçariam sua imagem pública e consolidariam seu eleitorado ao defender abertamente suas posições no tema, fossem elas contrárias ou favoráveis à redução. Mesmo em votações não nominais, os deputados faziam questão de usar a palavra para dizer como se posicionavam, registrando nos autos a todo momento suas escolhas.

Os argumentos focados no indivíduo e em sua escolha valorizam o recurso a casos concretos e o papel exemplar da punição para construir seu raciocínio, contribuindo de maneira mais evidente para a construção de um enquadramento da realidade que ultrapasse os limites do debate no qual foi produzido. Já os argumentos com um enfoque mais amplo do que o indivíduo frequentemente têm um caráter mais conjuntural, como as pesquisas de opinião ou as dificuldades de implementação do Estatuto da Criança e do Adolescente. Não são argumentos que apelem propriamente ao que é considerado justo ou injusto, mas sim ao que deve ser feito diante de realidades conjunturais mais imediatas. Enquanto os argumentos relacionados ao indivíduo têm conteúdo mais permanente, remetendo a valores considerados fundamentais, os demais pretendem lidar de maneira concreta com uma realidade considerada emergencial. Apesar da separação analítica, é importante lembrar que raramente algum parlamentar fica em apenas um dos argumentos para sustentar sua posição. O mais frequente foi a conjugação entre dois ou três dos elementos que serão apresentados a seguir. Para fins analíticos, dividimos os discursos em defesa da redução da maioridade penal em cinco argumentos diferentes, cujas frequência e centralidade variam nos discursos dos parlamentares. 
Enquanto os dois primeiros parecem menos relevantes para a grande maioria dos congressistas, os três últimos são repetidos constantemente e constituem o núcleo das posições dos defensores da aprovação da PEC.

\section{A falência do ECA}

Esse argumento não ocupa lugar central na defesa da matéria, mas é mobilizado em resposta aos opositores da medida, que frequentemente ressaltam o conteúdo social do problema da violência. Em todas as suas falas, os parlamentares contrários à redução reafirmam seu diagnóstico de que o crime e a violência existem em nossa sociedade por uma conjunção de fatores sociais, que vão muito além da compreensão individual ou da escolha de cada um. Eles ressaltam que a ausência de oportunidades de estudo e emprego, a fragilidade das políticas públicas de assistência social, saúde e cultura são elementos mais importantes do que o caráter de cada pessoa na explicação do problema que a redução busca enfrentar. Sustentam a necessidade de se expandir e garantir os direitos já consagrados na legislação como caminho para reduzir os índices de criminalidade, especialmente entre jovens.

Contra essa via de argumentação, os defensores da redução apresentam uma série de postulados que se relacionam de maneira mais direta com a conjuntura. O primeiro deles diz respeito à falência do Estatuto da Criança e do Adolescente. Promulgado em 1990 após um amplo debate da sociedade civil organizada, o estatuto teria falhado em garantir aos jovens um caminho longe da criminalidade. Muitas são as manifestações que percebem no ECA um excesso de direitos e uma incapacidade de lidar com os jovens em conflito com a lei. O ECA constituiria um problema em si, por sua excessiva permissividade - como exemplo cita-se o limite de três anos para a internação de menores. Mas há também os que sustentam que o problema do suposto aumento da violência praticada por jovens não decorre do texto do estatuto, mas sim dos governos que não souberam ou não quiseram aplicar seus dispositivos integralmente - e aqui o foco recai 
sobre os governos petistas. Os parlamentares que defendem a redução afirmam que se os jovens não tiveram oportunidade de estudar, é porque as gestões federais do PT falharam em garantir o acesso à educação de qualidade. Os cortes orçamentários realizados pela gestão de Dilma Rousseff no ano de 2015 foram mencionados com frequência para exemplificar aquilo que consideravam descaso do governo federal em relação à educação. Nesse caso particular, até se reconhece que políticas adequadas de educação pudessem seriam eficazes no esforço de evitar a ocorrência de atos violentos, mas os parlamentares afirmam que os resultados de políticas dessa natureza se dão apenas no longo prazo e a situação do país requereria medidas urgentes.

Em resumo, as falas aqui analisadas concordam em que o melhor caminho para lidar com a existência da criminalidade entre jovens seria a adoção de políticas públicas que oferecessem mecanismos adequados de proteção aos indivíduos considerados mais vulneráveis. No entanto, como essas políticas teriam sido insuficientes, era preciso agir em outra direção, enfrentando o tema pela via punitiva, que seria garantia de resultados mais rápidos. De certa maneira, é como se a falha dos estímulos positivos ensejasse a necessidade da punição, garantindo por uma via ou por outra a reprodução por parte dos jovens dos comportamentos considerados ideais.

\section{A vontade da maioria: as pesquisas de opinião}

Outro argumento de natureza conjuntural é aquele que evoca as pesquisas de opinião para defender a aprovação da matéria. Nesse caso, os parlamentares que defendem a redução utilizam pesquisas realizadas por institutos privados como indicadores da vontade do conjunto da população em torno do tema. A partir das pesquisas de opinião divulgadas, os deputados que defendem a redução passaram a afirmar que $90 \%$ da população seria favorável à aprovação da matéria e que, diante disso, o Congresso não teria alternativa que não fosse emendar a constituição. 
Os deputados favoráveis à redução ainda buscaram nas pesquisas de opinião elementos que permitissem responder às críticas de que a medida seria prejudicial apenas à parcela mais pobre da população. A partir de uma análise detalhada dos dados divulgados pelo Datafolha, eles afirmam que os estratos sociais com menor renda são os que oferecem maior apoio à medida. Segundo os defensores da redução, isso ocorre porque os mais pobres são os maiores prejudicados com a violência no país e, consequentemente, seriam os maiores defensores de punições mais duras contra aqueles que cometem atos violentos. Embora ainda faltem estudos mais aprofundados sobre as bases eleitorais de deputados que se elegem com plataformas punitivistas - como os integrantes da chamada bancada da bala -, um primeiro levantamento realizado em São Paulo por Faganello (2015) aponta para uma concentração de votos em bairros de classe média, tendo esses candidatos pouca penetração em bairros periféricos. Assim, não é possível corroborar - ainda que faltem estudos mais abrangentes a hipótese de que a convivência com a violência em espaços populares leva seus moradores a uma demanda por mecanismos punitivos cada vez mais duros. Não obstante, foi esse o vínculo que os defensores da redução pretenderam construir a partir das pesquisas de opinião divulgadas.

Ainda no debate em torno da necessidade de seguir ou não a suposta maioria, há outro ponto levantado pelos defensores da redução: para combater uma imagem negativa do parlamento seria preciso agir rapidamente. A maioria da população brasileira, em sua narrativa, não seria apenas favorável à redução da maioridade penal. Teria também uma imagem negativa do parlamento por sua inação. O fato de a matéria tramitar por 22 anos na Câmara era frequentemente apontado como um exemplo do descompasso existente entre representantes e representados. No curso dos debates em torno da matéria, foram frequentes as alusões à necessidade de os parlamentares terem coragem para avançar as votações, marcando uma nova posição em relação às legislaturas anteriores, que não conseguiram discutir e aprovar a medida. 
Embora conjunturais, esses argumentos foram mobilizados inúmeras vezes pelos defensores da redução da maioridade penal, representando estratégias importantes para a formação do bloco de parlamentares que buscou avançar a medida.

\section{O jovem de ontem e o jovem de hoje}

A justificativa apresentada pelo primeiro proponente da redução da maioridade penal na Câmara dos Deputados, Benedito Domingos, centravase na ideia de que a imputabilidade penal aos 18 anos fora estabelecida no código penal de 1940, que remetia a uma realidade que já não existia. De acordo com Domingos, o adolescente de 1940 era dotado de dispositivos mentais menos desenvolvidos do que os dos adolescentes de nosso tempo. Para sustentar tal afirmação, ele menciona uma série de transformações sociais que permitiriam ao jovem de hoje compreender melhor a natureza de seu vínculo com a sociedade e com o que é considerado correto. Dentre os elementos citados por Domingos, destacam-se a progressiva emancipação sexual dos jovens e a maior disponibilidade de informações, decorrente das evoluções tecnológicas que ampliaram o acesso aos meios de comunicação, como a televisão. Ele sustenta que com a mudança das condições sociais mudam também o indivíduo e sua capacidade de julgamento.

O menor de dezoito anos, considerado irresponsável e, consequentemente, inimputável, sob o prisma do ordenamento penal brasileiro vigente desde 1940, quando foi editado o Estatuto Criminal, possuía um desenvolvimento mental inferior aos jovens de hoje da mesma idade.

Com efeito, concentrando as atenções no Brasil e nos jovens de hoje, por exemplo, é notório, até ao menos atento observador, que o acesso destes à informação - nem sempre de boa qualidade - é infinitamente superior àqueles de 1940, fonte inspiradora natural dos legisladores para a fixação penal em dezoito anos. A liberdade de imprensa, a ausência de censura prévia, a liberação sexual, a emancipação e independência dos filhos cada vez mais prematura, a consciência política que impregna a cabeça dos adolescentes, a televisão como maior veículo de informação jamais visto ao alcance da quase totalidade 
dos brasileiros, enfim, a própria dinâmica da vida, imposta pelos tortuosos caminhos do destino, desvencilhando-se o avanço do tempo veloz, que não para, jamais. (...) Se há algum tempo atrás se entendia que a capacidade de discernimento tomava vulto a partir dos 18 anos, hoje, de maneira límpida e cristalina, o mesmo ocorre quando nos deparamos com os adolescentes com mais de 16. (Proposta de Emenda Constitucional no 171, protocolada pelo deputado Benedito Domingos - PP/DF, em 19/08/1993)

Tal argumento, apresentado em 1993, segue sendo mobilizado ao longo de todas as discussões sobre o tema, complementado por outras inovações tecnológicas como a internet. Na perspectiva dos deputados que mobilizam esse argumento, há algo de contingencial na defesa da redução da maioridade penal, tendo em vista que a capacidade de entendimento depende de uma série de transformações da sociedade. No entanto, o ponto central é a reflexão sobre a capacidade de entendimento do indivíduo. Nesse sentido, seus defensores não mencionam, em qualquer momento, os efeitos sociais desejados com a adoção dessa medida. Eles estão preocupados, fundamentalmente, com a relação entre a punição e o indivíduo que comete o crime. O autor da PEC, assim como aqueles que seguem e atualizam seu argumento original, acredita ser o discernimento de cada indivíduo o elemento central para determinar a punibilidade e o tipo de pena. Isso fica claro na recorrente afirmação de que o objetivo da PEC não é reduzir a criminalidade ou obter algum resultado concreto nas estatísticas sobre violência e sim fazer justiça aos que escolhem delinquir.

Se V.Exa., Parlamentar, acha que o jovem de 16 anos tem discernimento e tem capacidade para, quando mata ou quando estupra, saber o que está fazendo, ele tem de pagar pelos seus atos, porque senão a mensagem que fica para a sociedade é a da impunidade. E, para combater a impunidade, somos a favor da redução da maioridade penal. (Efraim Filho, APCD, 19/08/2015)

Sabemos que a redução da maioridade penal não resolverá o problema da segurança pública no país, mas, com certeza, dará limites e, o que é mais importante, fará justiça a homens e mulheres, pessoas de bem, que pagam seus impostos e que são vítimas desses menores — verdadeiros marginais disfarçados de menores. (Moura, APCD, 30/06/2015) 
Os parlamentares que se apoiam nesse ponto costumam fazer uma associação entre direitos e deveres. Segundo os mesmos, se os adolescentes têm maturidade o suficiente para gozar do direito de voto e, portanto, de definir em conjunto com a sociedade os destinos do país, eles devem ser considerados maduros o suficiente para compreender a natureza de seus atos, certos ou errados, e as consequências dos mesmos. Na grande maioria dos discursos em favor da redução, menciona-se o direito de voto aos 16 anos como medida para a afirmação acerca da capacidade de discernimento dos jovens. Segundo os parlamentares, se os adolescentes já têm certos direitos, devem ter também responsabilidades consideradas equivalentes. $\mathrm{O}$ contraponto a esse argumento feito pelos opositores da matéria levantava sempre a ideia de que os jovens de 16 anos ainda não estavam plenamente formados e que suas chances de recuperação seriam maiores em um sistema separado dos adultos. Para sustentar esse ponto, costumavam mencionar os índices de ressocialização observados nos sistemas juvenis e adultos.

Talvez pelo fato de não pretender atingir algum resultado mais concreto na sociedade e por remeter a um critério abstrato e permanente de justiça, tal argumento em favor da redução encontra facilidade em permanecer presente no discurso por tantos anos, atravessando diferentes conjunturas.

As argumentações centradas na capacidade dos indivíduos de discernirem sobre a natureza criminosa de seus atos remetem diretamente ao aspecto da culpa, base da demanda por punição a partir de uma perspectiva de reforma moral do indivíduo (Foucault, 2015). O que se pretende, aqui, não é reparar a sociedade pelos danos provocados ou mesmo produzir efeitos futuros como a redução da violência. O importante é reconhecer quando um indivíduo é culpado por seus atos e, a partir daí, estabelecer a pena como medida de justiça e reforma. Ainda que, somada a outros argumentos - alguns mais conjunturais e outros igualmente permanentes -, essa justificativa inicial para a proposição da PEC siga como núcleo duro da defesa da redução da maioridade penal, 
é o discernimento individual o elemento central desse debate, o que implica a defesa de uma perspectiva de sociedade e de ordem, como discutiremos mais adiante.

\section{A exemplaridade da punição}

Este argumento ressalta e complementa aquele discutido anteriormente. A pena, nesse conjunto de argumentos, já não é mais apresentada como um mecanismo que se relaciona exclusivamente com a compreensão do ato por parte de um sujeito, mas passa a carregar a possibilidade de prevenir novos atos de violência. A exemplaridade da pena, argumenta-se, produzirá um efeito sobre as próprias organizações familiares, que desenvolverão desde cedo maior preocupação com o destino de seus filhos.

A lei da redução da maioridade penal, que nós estamos votando hoje, vai servir para que os pais, as mães, os parentes de um jovem comecem a educá-lo melhor desde criança, mostrem a ele que o Brasil vai ser um país que tem leis. Vão dizer: "meu filho, quando você completar 16 anos, se cometer alguma coisa grave, você vai ser penalizado". E, com isso, nós teremos, sim, uma sociedade mais justa. As pessoas vão procurar educar melhor seus filhos. (Pereira, APCD, 20/08/2015)

Enquanto o argumento centrado no discernimento afirma constantemente a capacidade de julgamento dos jovens que entram em conflito com a lei, esse tipo de fala atenta para a possibilidade de se prevenir o delito a partir da ação familiar, por consequência, distribuindo entre o indivíduo e o seu meio mais imediato a responsabilidade por seus atos. Assim como no argumento anterior, remete-se ao âmbito privado a causa da desordem pública, em linha de continuidade com as perspectivas que organizaram o funcionamento da justiça e das instituições de atenção ao "menor" ao longo do século 20, no Brasil, em particular após a promulgação do Código de Menores de 1927 (Alvarez, 1989; Borges; Salla, 2018). A violação da lei e o consequente risco de violência a que estão submetidos todos os cidadãos têm origem na disfunção familiar, na incapacidade que as famílias têm de educar seus filhos adequadamente, de maneira que 
entendam a natureza de sua ligação com o conjunto da sociedade e os limites que devem respeitar para tomar parte nela.

Esquecem os defensores dessa ideologia progressista que, quando a família e o Estado falham completamente em prestar os cuidados básicos de saúde, assistência social e educação, desde o período gestacional do feto, passando pelos primeiros anos de vida da criança, quando os estímulos morais corretos o preparam para uma vida adulta produtiva e respeitadora dos direitos alheios, e culminando com a fase da adolescência em que o jovem deve estar protegido contra a influência das drogas, deve ter a oportunidade de lazer, cultura, esportes, educação, saúde, em um ambiente familiar e social harmonioso e pacífico, quando tudo isso falha e o adolescente opta pelo mundo do crime, o Direito Penal deve atuar, ainda que de modo excepcional e como última instância, para garantir os direitos da coletividade à ordem pública e à pacificação social. (Bessa, ACE, 08/04/2015)

Os defensores da redução igualam propositalmente, neste e em outros argumentos, o endurecimento das penas à certeza da punição. Eles sustentam que a garantia de impunidade leva ao confronto com a lei e isso requer a criação de mecanismos de punição mais rígidos, como se a mera existência desses garantisse a aplicação da pena em cada caso concreto. Ao afirmarem que a garantia da punição produziria uma série de transformações na maneira como pais educam seus filhos, os deputados começam a apontar para a estigmatização e criminalização de certos modos de sociabilidade, apontando para uma relação entre pobreza e violência. De acordo com Batista (2015), uma boa medida do processo de estigmatização das juventudes pobres pode ser observada na maneira como se produziram os estereótipos relacionados à droga no Brasil. Enquanto aos usuários de classe média se aplicou o estereótipo médico, aos jovens favelados e periféricos se dedicou o criminal. Não seriam apenas os indivíduos capazes de discernir o certo do errado a serem responsabilizados, mas também seus pais negligentes que não estiveram presentes no momento de estipular os limites que deveriam ser respeitados por seus filhos. Nesse sentido, são frequentes as menções aos "jovens abandonados", "jovens sem limites", que também remetem a expressões historicamente empregadas, inclusive 
nas instituições do Estado, para abordar o adolescente enquanto problema, como no caso de "menor abandonado".

\section{A resposta às vítimas: a força do exemplo e a dor dos familiares como eixo de argumentação}

Ao longo de todo o debate, houve uma tensão entre os defensores da redução e seus opositores no que diz respeito a quais deveriam ser os parâmetros utilizados para julgar a pertinência de aprovar uma matéria dessa natureza. Os opositores da PEC afirmaram diversas vezes a necessidade de centrar os debates em torno da análise de estatísticas e informações produzidas por diversos atores que trabalham diretamente com os temas da infância e adolescência - organismos da Organização das Nações Unidas, órgãos de governo, organizações não governamentais e outros atores da sociedade civil, como a Organização dos Advogados do Brasil (OAB) ou a Confederação Nacional dos Bispos do Brasil (CNBB). Por outro lado, os defensores da medida se concentraram nos exemplos de casos de violência praticados por menores para exigir a aprovação da redução. Tal divergência revela uma diferença de concepção em torno de que função deve cumprir uma lei. Os parlamentares contrários à redução afirmam que a lei deve servir para resolver um problema social. Nesse caso, se o problema é a violência e a criminalidade, seria preciso identificar que tipo de legislação poderia reduzir os índices de tais ocorrências. Já os defensores da PEC apresentam a lei, nesse caso, como resposta da sociedade - através do Estado - aos indivíduos e familiares que sofrem com a dor causada por um ato de violência. Nesse sentido, a punição funcionaria como mecanismo de reparação e não apenas como instrumento de dissuasão.

As vítimas e familiares são apresentados, então, como pessoas que têm um lugar de fala privilegiado para opinar sobre a necessidade de se punir ou não os responsáveis por seu sofrimento. Vera Batista (2008) ressalta que a centralidade conferida à fala das vítimas de violência é um componente fundamental do processo de encarceramento em massa ocorrido no país 
nas últimas três décadas. A autora considera que o tom emotivo das falas é importante para a expansão do poder punitivo, na medida em que produz um efeito de sensibilização. No mesmo sentido, Wieviorka (1997) tem abordado a importância dessa fala da vítima como uma das características do que chama de novo paradigma da violência. A deputada Keiko Ota (PSB-SP), mãe de vítima de violência, é frequentemente mencionada por seus colegas como alguém cuja opinião deve ter um peso maior.

Como todos sabem eu sou a mãe de vítima de violência e como parlamentar represento aqui nesta casa milhares de vítimas e seus familiares de todo o Brasil. Fico aqui impotente e envergonhada de tanta violência e impunidade em nosso país. Mais de 56 homicídios por ano sendo que uma boa parte destas tem pelo menos um menor envolvido nesses crimes. $\mathrm{O}$ fato é que eles são extremamente violento e agem de forma natural como se a vida não tivesse valor. (...) Eu convivo diariamente com essas mães. (...) Percebi o quanto essa dentista sofreu nas mãos desses bandido. Imaginem todos vocês estar com as mãos amarradas, suplicando pela sua vida e mesmo assim os criminosos não tiveram a compaixão e atearam fogo nela.

Gente, eu pergunto, aonde estão os direitos humano para essa família?

(no fundo ouve-se alguém gritando: só pra vagabundo)

Um deles era menor e foi justamente esse que foi mais violento.

Temos aqui dois casos: a filha da Marisa e o filho da Juraci. Eles perderam a vida por motivos fúteis, por um aparelho celular. Que vida! Eu sei o que é esta dor, a dor de perder um filho. Não a quero para ninguém. Meu filho já foi, mas eu luto porque não consigo entender como uma pessoa pode tirar a vida de outra. Então, vamos colocar no dia de hoje um sorriso no rosto de todas as mães vítimas de violência neste país. (Manifestação nas galerias. Palmas.) (Ota, APCD, 30/06/2015)

Cabe ressaltar que alguns dos parlamentares envolvidos nas discussões pautam sua atuação política pela proximidade com vítimas de violência. Eles mencionam os contatos com familiares de vítimas e as expectativas depositadas na aprovação de mecanismos punitivos como forma de se fazer justiça. 
Sr. Presidente, Srs. Deputados, Sras. Deputadas, nesse final de semana, eu fui a dois velórios. Em um deles, o Vice-Prefeito estava enterrando seu pai, de 94 anos; no outro, os pais estavam enterrando um menor que levou três tiros na cara de outro adolescente, em Uberaba. Estive lá e a família me questionou: "O que vocês, deputados, estão fazendo lá na Câmara que não tomam uma atitude contra essa criminalidade, que está assolando as famílias brasileiras?" Eu respondi que o Presidente colocaria em votação, nesta terça-feira, a PEC da Redução da Maioridade Penal.

Assim eu ouvi dessas mães, como ouvi desses pais, e ouvi na minha carreira de 35 anos de Polícia vários pedidos de providência. (Moreira, APCD, 30/06/2015)

A legislação penal seria, segundo essa perspectiva, uma das ferramentas a serem empregadas na guerra contra os que atacam a sociedade. Os exemplos de violência trazidos eram quase sempre acompanhados de considerações sobre a incapacidade do ECA de promover punições adequadas ou então sobre a inimputabilidade penal como garantia de impunidade absoluta. A menção a casos de violência praticados por menores foi um dos recursos retóricos mais mobilizados na defesa da redução da maioridade penal. No decorrer de todas as etapas da tramitação da PEC, tais casos foram citados em conjunto com os outros argumentos aqui discutidos. Sempre em tom de comoção ou indignação, os apelos aos exemplos concretos se anunciavam como maneiras de pensar para além das estatísticas.

\section{Representações do(s) jovem(s) nos discursos parlamentares: o bom jovem x bandidos travestidos de jovens}

Todos os argumentos apresentados em favor da redução da maioridade penal convergem para um mesmo ponto, que é a definição de um modelo de comportamento que deve ser seguido por todos os cidadãos. A defesa de medidas punitivas sempre carrega consigo, inerentemente, um postulado normativo. Qualquer restrição de comportamento implica a afirmação de outros comportamentos que devem ser adotados. No caso da redução, não se trata apenas de dizer que os jovens não devem cometer atos violentos. Acompanhada dessa afirmação vem a exigência de que eles organizem 
sua vida de uma maneira específica, o que aparece de forma explícita na fala de diversos parlamentares.

Sr. Presidente, Sras. e Srs. Deputados, a redução da maioridade penal é uma realidade, e o Brasil não aceitará que nos acovardemos. Chegou a hora, Deputado Júlio Cesar; não tem mais jeito. Se reduzirmos a maioridade penal hoje, nós não vamos buscar nenhum aluno em banco de faculdade para colocar na cadeia; nós não vamos buscar nenhum adolescente no banco de uma igreja para colocar na cadeia; nós vamos buscar criminosos, esses, sim, porque o lugar deles é na cadeia! (Palmas nas galerias.) O lugar de adolescente inocente é na faculdade, é na escola, mas o lugar de adolescente que sequestra, de adolescente que estupra, como em meu Estado, de adolescente que mata é na cadeia! (Palmas nas galerias.). (Freire, AP, 30/06/2015)

O que eles estão afirmando, no fundo, é que todos os jovens que se desviem desse modelo de comportamento estão rompendo seu vínculo com o conjunto da sociedade. Se a pena é entendida, dentre outras coisas, como um mecanismo de reparação à sociedade pelos danos causados por um indivíduo, o desvio em relação a um comportamento considerado normal seria o parâmetro para a definição de quando este vínculo foi rompido e, consequentemente, quando a sociedade foi atacada. Isso acontece quando o jovem assume qualquer conduta de vida que não implique diretamente a reificação da ordem vigente.

Os jovens devem organizar suas vidas em torno de um tripé composto pela família, religião e trabalho ou estudo (formação para o trabalho no futuro). O bom jovem é aquele que privilegia suas relações familiares, que se concentra nos seus estudos e, fundamentalmente, que quer trabalhar. Ser produtivo é o critério mais importante na definição daquele que é considerado o cidadão ideal na perspectiva dos parlamentares que defendem a redução.

Sr. Presidente, eu gostaria de fazer um alerta aqui às Sras. e aos Srs. deputados com relação à votação que fazemos hoje. Quando nós erramos? Erramos quando aprovamos o ECA, lá atrás, e não demos oportunidade de os jovens de 14 anos trabalharem. (Russomanno, APCD, 30/06/2015) 
De acordo com Foucault (2005), para garantir a integração dos indivíduos na produção e para proteger a riqueza das classes despossuídas, fortalece-se uma série de instituições que, enquanto sequestram e controlam a maior parte do tempo dos indivíduos, buscam normalizá-los segundo critérios morais que evitam os saques ou outras formas de assalto à riqueza, como o ócio, as festas os quaisquer outros hábitos que reduzam a produtividade. Nesse sentido, a escola, os hospitais, os hospitais psiquiátricos e, obviamente, as prisões têm algo em comum: são espaços onde os indivíduos são vigiados, controlados e, principalmente, moralizados e normalizados. Na realidade, seja quando se trata do indivíduo perfeitamente integrado à ordem - que vai à escola, à fábrica, à igreja -, seja quando se fala do indivíduo que rompe seu vínculo com a sociedade - o marginal -, o horizonte normativo é sempre o mesmo, o controle do tempo de vida e também do corpo que deve ser funcional.

Ninguém está dizendo que a redução da maioridade penal vai resolver todos os problemas, mas nós precisamos começar a adotar políticas mais rigorosas, pensando no cidadão de bem. Nós não temos outra política, a médio e curto prazo, a não ser segregar da sociedade essas pessoas que são criminosos contumazes. Esse pessoal que está contra a redução da maioridade penal está mais preocupado com a redução dos marginais do que eles próprios. Oitenta e sete por cento dos presos são reincidentes contumazes, não se recuperam, não querem se recuperar.

Nós não podemos continuar adotando essa mesma política, preocupados somente com a recuperação do marginal. Temos que começar a ter um olhar no cidadão de bem, o cidadão que está trancado em casa, acuado, com medo de sair às ruas. (Capitão Augusto, APCD, 01/07/2015)

Entretanto, à diferença dos discursos analisados por Foucault no momento de construção dos sistemas penais europeus, os parlamentares brasileiros que reivindicam a redução da maioridade penal não enunciam um horizonte de correção e reintegração dos indivíduos. Pautados pela lógica da guerra, sustentam a segregação e, em casos extremos, a eliminação dos que ameaçam a "sociedade de bem". As considerações sobre o que é 
o bom jovem ou cidadão de bem estabelecem um normal a partir do qual se define o que é marginal. Por essa razão, as referências mais frequentes aos jovens em conflito com a lei se dão através desse termo: marginais. No caso da redução, ele aparece com recorrência ainda maior do que "bandidos", outra forma de tratamento bastante comum - frequente nos debates sobre o desarmamento civil, por exemplo - quando querem fazer menção aos jovens em conflito com a lei.

Está certo que as nossas polícias vão trabalhar muito para tirar esses marginais da rua, esses marginais travestidos de menores, esses homens de 16 anos que se dizem menores para matar os pais de família, para estuprar as filhas do povo brasileiro. (Bessa, APCD, 19/08/2015)

Mais uma vez, nota-se o viés higienista das falas, mais preocupadas com a limpeza e exclusão dos marginais do que com a projeção de um futuro que os integre em alguma medida. Não por acaso, os jovens militantes ${ }^{6}$ que se organizaram para acompanhar os debates na Câmara e pressionar os deputados contra a PEC 171-93 são frequentemente comparados aos jovens em conflito com a lei, por parte dos deputados que defendem a medida. Em suas perspectivas, não são apenas as condutas violentas que representam um problema a ser enfrentado, mas qualquer postura que coloque em xeque a maneira como a sociedade está organizada atualmente. O que está em jogo é o controle da energia dos jovens segundo os parâmetros estabelecidos pelos que defendem a permanência do mundo tal como ele é. Nesse sentido, quaisquer práticas que impliquem contestação das

${ }^{6}$ Durante todo o processo de tramitação da PEC as sessões de debates foram acompanhadas por estudantes e militantes contrários à medida. Além das organizações tradicionais de representação estudantil, como a UNE e a UBES, houve outros movimentos que se articularam na sociedade civil com o objetivo de combater a redução da maioridade penal, dentre os quais destaco o Amanhecer, que realizou uma série de intervenções em espaços públicos de todo o país, além de ter montado caravanas de estudantes à Brasília para acompanhar a tramitação da medida e as votações no plenário. Durante todo o processo, tais estudantes e militantes foram hostilizados pelos parlamentares favoráveis à redução, sendo que em mais de uma ocasião foi determinado o esvaziamento das galerias ou setores da Câmara destinados ao acompanhamento público dos debates. As referências a esses jovens como vagabundos, pagos por partidos ou mesmo as comparações em relação aos jovens considerados marginais foram frequentes, reforçando o ponto aqui construído.

Sociologias, Porto Alegre, ano 23, n. 58, set-dez 2021, p. 168-203. 
instâncias de poder e autoridade existentes podem ser comparáveis entre si, do crime violento à militância política.

Essa plateia que está aqui que eu entendo que é tal qual o maior levando o menor pro crime. Aqui está cheio de maiores trazendo essa meninada, esses menores pra bagunçar essa comissão. (Bessa, ACCJC, 24/03/2015)

Se o bom jovem é aquele que centra sua vida em torno do tripé família, religião e trabalho, as formas de vida que questionam a organização tradicional da família, a ausência de valores religiosos e o ócio são entendidos como elementos que contribuem para compreender uma suposta decadência moral que marcaria nossa sociedade, abrindo espaço para o aumento da violência. As relações entre debilidade moral e criminalidade foram desenvolvidas em quase todos os discursos analisados neste trabalho. $\mathrm{O}$ argumento de que a ausência de mecanismos de integração produz um segmento da sociedade disposto a atacar seus pares é recorrente pelo menos desde os anos 1980 no tratamento do tema da violência em nossa sociedade. Trata-se de um tema clássico na literatura sobre crime, punição e risco (Foucault, 2015, Castel, 2004).

Por isso, alguns dos parlamentares falam em vagabundagem, drogas e até mesmo cirurgias de mudança de sexo ou "ideologia de gênero" como aspectos que formam um ambiente propício à violência. O que está em jogo é a corrupção de todas as formas de autoridade como raiz da violência, tema fundamental do conservadorismo na atual conjuntura.

Sr. Presidente, Sras. Infelizmente, hoje, no país em que nós vivemos, aliás, no mundo, a maior instituição da Terra, que é a família, está fragilizada. Agora, ela está fragilizada porque nós proibimos o jovem de trabalhar. Ela está fragilizada porque alguns defendem que a cartilha desperte a sexualidade de crianças ainda no maternal ou na alfabetização. Isso é que fragiliza a família; isso é que está deixando as nossas famílias trêmulas. (Freire, APCD, 01/07/2015)

A separação entre o bom jovem e os que desviam desse padrão de comportamento é essencial para pensar os fundamentos da manutenção da ordem. Na perspectiva dos parlamentares que defendem a redução, é 
preciso legislar para que as pessoas que trabalham continuem trabalhando e para que as pessoas que têm família continuem organizando a vida em torno de suas famílias, que funcionam não apenas como espaços de moralização, mas também de reprodução de mão de obra. Esse é o sentido normativo da redução da maioridade penal: reforçar determinados papéis sociais que devem ser desempenhados pelos cidadãos de bem.

Sr. Presidente, Srs. Deputados, esta é uma noite memorável em que vamos, sem dúvida, aprovar a proposta de emenda à Constituição que ampara os homens de bem e pune os bandidos. A lei é para quem anda à margem dela, ou seja, para os bandidos. Os bandidos têm sido muito bem representados aqui no parlamento. Precisamos defender, sim, os homens de bem desta nação. Inclusive, tenho uma sugestão aos senhores que estão com pena desses bandidos travestidos de menores: levem-nos para casa. Botem um ou dois em suas casas e verão o que é bom para tosse! Precisamos estabelecer limites e punições. E a hora é esta. Por isso, Sras. e Srs. deputados, votemos "sim" à redução da maioridade penal, em nome das famílias brasileiras e da segurança dos homens de bem desta nação. (Teixeira, APCD, 01/07/2015)

A gestão das populações consideradas vulneráveis - e, logo, perigosas - por meio de políticas punitivas constitui o ponto central deste texto. Os discursos selecionados para análise confirmam a hipótese de que a juventude recebe atenção especial dos que defendem sempre saídas punitivas para os conflitos sociais.

\section{Conclusão}

A presente pesquisa buscou contribuir para elucidar de que maneira os debates parlamentares podem contribuir para a circulação de perspectivas específicas sobre a relação entre punição e ordem social. Ao analisar a maneira como deputados, em especial os defensores de medidas punitivas, articulam seus discursos, abrimos uma janela para visões de mundo mais amplas, que são enunciadas em diferentes espaços e encontram nos debates parlamentares um de seus pontos de fixação. Percebemos, portanto, que as falas sobre a redução da maioridade penal e as expectativas em relação 
a seus possíveis efeitos vão muito além da preocupação com jovens que eventualmente cometam delitos. Frequentemente os discursos mobilizam a imagem de jovens violentos, cometendo crimes bárbaros, mesmo quando a maioria dos adolescentes cumprindo medida socioeducativa entra no sistema por outras causas. ${ }^{7}$ Da mesma maneira, são frequentes as falas que se referem aos jovens como fonte de risco e, eventualmente de violência, quando os dados indicam que os jovens brasileiros têm sido, na realidade, as vítimas mais corriqueiras da violência no país. Nesse sentido, entender os discursos parlamentares em defesa de punições mais duras aos adolescentes em conflito com a lei não significa elaborar contra-argumentação que desmonte uma por uma as estratégias de inserção desses representantes no debate público. Não se trata apenas de disputas decorrentes de informação imperfeita. Antes, precisamos ir além e compreender quais são as imagens e os projetos de sociedade que estruturam os discursos que analisamos e, num momento futuro, compreender quais são as condições sociais que permitem sua atualização ao longo de tantos e tantos anos.

Pedro Rolo Benetti é Doutor em Ciência Política e pesquisador com bolsa de pós-doutorado no Núcleo de Estudos da Violência da Universidade de São Paulo.

$\triangle$ pedrorolobenetti@gmail.com

\section{Referências}

1. ALVAREZ, Marcos C. A emergência do Código de Menores de 1927: uma análise do discurso jurídico e institucional de assistência e proteção aos menores. 1990. Dissertação (Mestrado em Sociologia) - Faculdade de Filosofia, Letras e Ciências Humanas, Universidade de São Paulo, São Paulo, 1990.

2. BATISTA, Vera M. Direitos (e) humanos no Brasil contemporâneo. Jura Gentium, 2008. (Seção "Rule of Law and Human Rights in Latin America"). Disponível em: https://www.juragentium.org/topics/latina/pt/malaguti.htm

${ }^{7}$ Para usar como exemplo, um estudo do governo de 2017, apenas 8,5\% dos atos infracionais naquele ano foram homicídios, mais de $60 \%$ são crimes patrimoniais. Ver https://www.gov.br/ $\mathrm{mdh} / \mathrm{pt}$-br/navegue-por-temas/crianca-e-adolescente/LevantamentoAnualdoSINASE2017. pdf, acessado em 02/08/2021. 
3. BATISTA, Vera M. Estado de polícia. In: KUCINSKI, Bernardo et al. Bala perdida: a violência policial no Brasil e os desafios para sua superação. São Paulo: Boitempo, 2015.

4. BAZÍlIO, Luiz C. Trabalho do adolescente: história, política e legislação. In: BAZÍLIO, Luiz C. et al. Infância tutelada e Educação: história, política e legislação. Rio de Janeiro: Ravil, 1998.

5. BORGES, Viviane; SALLA, Fernando. A gestão da menoridade sob o Serviço Social de Assistência e Proteção aos Menores de São Paulo (1930-1940): encruzilhada de saberes. Saúde e Sociedade, v. 27, p. 326-337, 2018. https://doi. org/10.1590/S0104-12902018180139

6. BRASIL. Estatuto da Criança e do Adolescente. Lei no 8.069 de 13 de julho de 1990. Dispõe sobre o Estatuto da Criança e do Adolescente e dá outras providências. Diário Oficial da União, 1990. Disponível em: http://www.planalto. gov.br/ccivil_03/leis/L8069.htm.

7. BRAUDEL, Fernand. História e ciências sociais: a longa duração. Revista de História, v. 30, n. 62, p. 261-294, 1965.

8. BUDÓ, Marilia de N. A redução da maioridade penal na Folha de S. Paulo: da razão à emoção. Revista Eletrônica do Curso de Direito da UFSM, v. 10, n.1, p. 94-125, 2015a. https://doi.org/10.5902/1981369418649

9. BUDÓ, Marília de N. Vítimas e monstros: a construção social do adolescente infrator do centro à periferia. Revista Espaço Acadêmico, v. 15, p. 41-52, 2015b.

10. BUDÓ, Marília de N.; CAPPI, Riccardo. Punir os jovens? A centralidade do castigo nos discursos midiáticos e parlamentares sobre o ato infracional. Belo Horizonte: Letramento, 2018.

11. CALDEIRA, Teresa P. do R. Direitos humanos ou "privilégios de bandidos". Novos Estudos Cebrap, v. 30, n. 1991, p. 162-74, 1991.

12. CALDEIRA, Teresa P. do R. Cidade de muros: crime, segregação e cidadania em São Paulo. São Paulo: Editora 34, 2000.

13. CAMPOS, Marcelo da S. Mídia e política: a construção da agenda nas propostas de redução da maioridade penal na Câmara dos Deputados. Opinião Pública, v. 15, n. 2, p. 478-509, 2009.

14. CAMPOS, Marcelo da S.; SALLA, Fernando; ALVAREZ, Marcos C. Redução da maioridade penal e Congresso Nacional: crimes violentos, mídia e populismo penal. Revista Brasileira Adolescência e Conflitualidade, n. 13, p. 358-378, 2015.

15. CASTEL, Robert. La inseguridad social zqué es estar protegido?. Buenos Aires: Ediciones Manantial, 2004.

16. CHALOUB, Jorge. A Constituição e o cenário político: um olhar sobre a crise. Escuta - Revista de Política e Cultura. Disponível em: https://revistaescuta. wordpress.com/2016/01/13/31/. 
17. CORTE REAL, Fabíola G. V.; CONCEIÇÃO, Maria I. G. Representações sociais de parlamentares brasileiros sobre a redução da maioridade penal. Psicologia: Ciência e Profissão, v. 33, p. 656-671, 2013. https://doi.org/10.1590/S141498932013000300011

18. FAGANELLO, Marco A. Bancada da bala: uma onda na maré conservadora. In: VELASCO E CRUZ, Sebastião et al. (orgs.). Direita, volver! O retorno da direita e o ciclo político brasileiro. São Paulo: Editora Fundação Perseu Abramo, 2015.

19. FIGUEIREDO, Argelina C.; LIMONGI, Fernando de M. P. Executivo e Legislativo na nova ordem constitucional. Rio de Janeiro: Editora FGV, 1999.

20. FOUCAULT, Michel. A ordem do discurso. 5. São Paulo: Loyola, 1999.

21. FOUCAULT, Michel. Em defesa da sociedade. São Paulo: Martins Fontes, 2005.

22. FOUCAULT, Michel. A sociedade punitiva: curso no Collège de France (19721973). São Paulo: Editora WMF Martins Fontes, 2015.

23. GARLAND, David. A cultura do controle: crime e ordem social na sociedade contemporânea. Rio de Janeiro: Instituto Carioca de Criminologia Revan, 2008.

24. HIGA, Gustavo L.; ALVAREZ, Marcos C. Humanização das prisões e pânicos morais: notas sobre as "Serpentes Negras". Estudos Avançados, v. 33, p. 69-90, 2019.

25. SIMON, Jonathan; SILVESTRE, Giane. Governing through crime. In: CARLEN, Pat; FRANÇA, Leandro A. (orgs.). Alternative criminologies. Londres: Routledge, 2017. p. 73-91.

26. WIEVIORKA, Michel. O novo paradigma da violência. Tempo social, v. 9, p. 5-41, 1997. https://doi.org/10.1590/S0103-20701997000100002 


\section{Anexos}

Quadro 1- Lista de parlamentares citados

\begin{tabular}{|l|l|l|}
\hline \multicolumn{1}{|c|}{ NOME } & PARTIDO & CITADO NO TEXTO \\
\hline Andre Moura & PSC & MOURA \\
\hline Benedito Domingos & PP & DOMINGOS \\
\hline Capitão Augusto & PR & CAPITÃO AUGUSTO \\
\hline Celso Russomanno & PRB & RUSSOMANO \\
\hline Delegado Edson Moreira & PTN & MOREIRA \\
\hline Efraim Filho & DEM & FILHO \\
\hline Ezequiel Teixera & PMB & TEIXEIRA \\
\hline Keiko Ota & PSB & OTA \\
\hline Laerte Bessa & PSC & BESSA \\
\hline Mauro Pereira & PMDB & PEREIRA \\
\hline Silas Freire & PR & FREIRE \\
\hline
\end{tabular}




\section{Anexos}

Quadro 2 - Lista de documentos citados

\begin{tabular}{|c|c|c|}
\hline \multicolumn{3}{|c|}{ TABELA DE DOCUMENTOS } \\
\hline DATA & TÍTULO & SIGLA $(*)$ \\
\hline $5 / 15 / 13$ & $\begin{array}{l}\text { Voto em separado do deputado Efraim Filho - COMISSÃO DE } \\
\text { CONSTITUIÇÃO E JUSTIÇA E CIDADANIA/PROPOSTA DE } \\
\text { EMENDA À CONSTITUIÇÃO Nº 171, DE } 1993\end{array}$ & ACCJC \\
\hline $3 / 17 / 15$ & $\begin{array}{l}\text { Reunião ordinária no 0089/15 - COMISSÃO DE } \\
\text { CONSTITUIÇÃO E JUSTIÇA E CIDADANIA }\end{array}$ & ACCJC \\
\hline $3 / 24 / 15$ & $\begin{array}{l}\text { Audiência Pública no 0138/15 - COMISSÃO DE } \\
\text { CONSTITUIÇÃO E JUSTIÇA E CIDADANIA }\end{array}$ & ACCJC \\
\hline $3 / 25 / 15$ & $\begin{array}{l}\text { Voto em separado do deputado Capitão Augusto - COMISSÃO } \\
\text { DE CONSTITUIÇÃO E JUSTIÇA E CIDADANIA/PROPOSTA DE } \\
\text { EMENDA À CONSTITUIÇÃO N } 171 \text {, DE } 1993\end{array}$ & ACCJC \\
\hline $3 / 30 / 15$ & $\begin{array}{l}\text { Reunião Extraordinária no 0196/15 - COMISSÃO DE } \\
\text { CONSTITUIÇÃO E JUSTIÇA E CIDADANIA }\end{array}$ & ACCJC \\
\hline $3 / 31 / 15$ & $\begin{array}{l}\text { Reunião Ordinária no 0200/15 - COMISSÃO DE } \\
\text { CONSTITUIÇÃO E JUSTIÇA E CIDADANIA }\end{array}$ & ACCJC \\
\hline $4 / 8 / 15$ & $\begin{array}{l}\text { Reunião 0262/15 - COMISSÃO ESPECIAL PEC 171/93 } \\
\text { MAIORIDADE PENAL }\end{array}$ & ACE \\
\hline $6 / 9 / 15$ & $\begin{array}{l}\text { Parecer do Relator da COMISSÃO ESPECIAL PEC 171/93 } \\
\text { MAIORIDADE PENAL }\end{array}$ & ACE \\
\hline $6 / 17 / 15$ & $\begin{array}{l}\text { Reunião da COMISSÃO ESPECIAL PEC 171/93 MAIORIDADE } \\
\text { PENAL }\end{array}$ & ACE \\
\hline $6 / 30 / 15$ & Reunião Deliberativa Extraordinária no 176.1.55.O - PLENÁRIO & APCD \\
\hline $7 / 1 / 15$ & Reunião Deliberativa Extraordinária no 179.1.55.O - PLENÁRIO & APCD \\
\hline $8 / 19 / 15$ & Reunião Deliberativa Extraordinária no 231.1.55.O - PLENÁRIO & APCD \\
\hline
\end{tabular}

Recebido: 27 ago. 2021

Aceito: 01 dez. 2021 